\title{
TITLE: Did the Crew of the Submarine H.L. Hunley Suffocate?
}

\section{SHORT TITLE: Did Suffocation Sink the Hunley?}

AUTHORS: Rachel M. Lance ${ }^{1,2 *}$, Richard Moon ${ }^{3}$, Michael Crisafulli ${ }^{4}$, Cameron R. "Dale" Bass $^{1}$

\author{
AFFILIATIONS: \\ ${ }^{1}$ Duke University, Department of Biomedical Engineering. 1427 CIEMAS, 101 Science Drive, \\ Box 90281, Durham, NC 27705 \\ ${ }^{2}$ Naval Surface Warfare Center Panama City Division, Code E15 Underwater Systems \\ Development and Acquisition. 110 Vernon Dr, Panama City, FL 32407 \\ ${ }^{3}$ Duke University Medical Center, Department of Anesthesiology. DUMC 3094, Durham, NC \\ 27710 \\ ${ }^{4}$ Independent Researcher, www.VernianEra.com. 296 Ferndale Dr, Binghamton, NY 13905 \\ CORRESPONDING AUTHOR: \\ Rachel Lance \\ 1427 CIEMAS, 101 Science Dr, box 90281, Durham, NC 27705 \\ (919)660-5167 \\ Rachel.lance@duke.edu
}

KEYWORDS: hypoxia, hypercapnia, Hunley, submarine, sinking 


\begin{abstract}
.
On the evening of February $17^{\text {th }}, 1864$, the Confederate submarine H.L. Hunley attacked the Union ship USS Housatonic outside Charleston, South Carolina and became the first submarine in history to successfully sink an enemy ship in combat. One hypothesis for the sinking of the Confederate submarine H.L. Hunley is that the crew, in the enclosed vessel, suffered a lack of oxygen and suffocated. This study estimates the effects of hypoxia and hypercapnia on the crew based on submarine gas volume and crew breathing dynamics. The calculations show the crew of the Hunley had a minimum of 10 minutes between the onset of uncomfortable hypercapnia symptoms and danger of loss of consciousness from hypoxia. Based on this result and the location of the crew when discovered, hypoxia and hypercapnia do not explain the sinking of the world's first successful combat submarine.
\end{abstract}

\title{
Introduction.
}

Confederate military commanders hoped that the Hunley could sink some of the Union ships blockading Charleston harbor, and thereby end the Union blockade [1,2]. Several military submarines had previously been constructed, such as Alfred Bushnell's Turtle during the Revolutionary War, and the Confederate vessels Pioneer and American Diver, but before the Hunley none had been successful in combat [3].

The Housatonic was quickly sunk by the Hunley's torpedo, and five members of her crew were killed. However, the Hunley disappeared immediately after its attack, and even though it was raised from the ocean floor in 2000, the cause of its sinking remains a mystery [4]. It is possible that the vessel was sunk because the crew, in their sealed volume, consumed their limited oxygen supply and succumbed to the effects of hypoxia and/or hypercapnia. This study analyzes limits on the air supply for the crew of the H.L. Hunley.

\section{Background. HISTORY OF THE SUBMARINE}

Before its final disappearance on February $17^{\text {th }}$, the Hunley had sunk twice on training missions, killing a total of 13 crewmen. The Hunley was powered by a hand cranking mechanism that was turned by 7 crewmen, with an $8^{\text {th }}$ crewman who served as the commander and navigator [5, 6]. In light of the previous sinkings of the Hunley, the crew was reportedly forbidden from making the submarine negatively buoyant, even on the night of its attack [7], and was to attack on the surface of the water without fully submerging. This command made the vessel safer to operate and also provides valuable information about its position in the water column because historical drawings are available detailing the attack position [2]. Figure 1 shows a detailed artistic reconstruction of the H.L. Hunley as she would have appeared at the time of her sinking. The figure shows the torpedo in a lowered position. It should be noted that the exact angle of the spar and torpedo relative to the body of the vessel are still uncertain, but that their positions do not impact the results of this study. 
Figure 1. 3D reconstruction of the H.L. Hunley at the time of her sinking. More information and detailed views of the reconstruction can be found at the website http://vernianera.com/Hunley/

\section{AIR EXCHANGE}

Historical accounts describe a bellows and snorkel tubes designed to circulate air within the body of the submarine, and indeed such a system was discovered upon the vessel's recovery $[2,5]$. However, little is known about how well this system functioned, or if it functioned at all. Former crewman William Alexander wrote that the bellows never functioned properly, and that fresh air was instead obtained by opening the conning tower hatches every 20 minutes $[2,8]$. Other historical accounts were similarly dismissive of the bellows and snorkel system [8]. Indeed, the bellows are not included on any known historical drawings or diagrams, perhaps indicating that the draftsmen may have neglected the nonfunctional structure. Aside from the bellows system, the vessel had no means of taking in fresh air other than opening the hatches. This analysis was conducted under the assumption that the historical accounts are accurate, and that the bellows did not function to ventilate the atmosphere of the submarine. This is a conservative assumption since increased ventilation would delay the effects of either hypoxia or hypercapnia.

The crew was acutely aware of the risks of hypoxia in a closed environment, and performed tests to determine the duration of their oxygen supply [2]. The test consisted of holding the vessel submerged, too deep for any possible operation of the bellows, while the crew performed their normal cranking operations with a lighted candle burning.

\section{ARCHAEOLOGICAL DISCOVERIES}

Since its raising in 2000, several archaeological discoveries have been made regarding the Hunley. Most importantly, when the sediment was excavated from the inside of the Hunley, it was discovered that the remains of all eight crewmembers were still seated at their stations along the crank [9]. The Chairman of the Friends of the Hunley at the time, Warren Lasch, was quoted describing the remains: "The crewmembers' remains being discovered at their stations indicated both a recognition and acceptance of their fate... evidence seems to suggest more and more that the final moments were quick and decisive."[9] Lieutenant George Dixon, who manned the forward command position below the fore conning tower, was described as "right there in his duty station slumped over to one side with his legs up near the bulkhead, exactly where he would have been if he was on duty."[10]. Additionally, geological analysis of the sediment and macrofauna showed that there was a "calm period of little to no deposition" following sinking, indicating that the hull was intact when it sank $[11,12]$.

\section{RESPIRATION}

In clinical research, hand-pedaled arm ergometers are frequently used to measure and control levels of exercise performed by human test subjects; the cranking motion of these ergometers is biomechanically similar to the cranking motion used to propel the Hunley [13]. In 
addition to hypoxia, concurrent hypercapnia from increased carbon dioxide $\left(\mathrm{CO}_{2}\right)$ levels for personnel rebreathing gas within an enclosed space is also important. Unlike hypoxia, which may not be evident to sufferers, hypercapnia can cause overt and identifiable symptoms such as sensation of choking, shortness of breath, chest pain, tingling, trembling, headache, nausea, and psychological fear and discomfort [13-15]. The amount of carbon dioxide produced is calculated by multiplying the oxygen consumption by the respiratory exchange ratio (RER), a fractional ratio describing the rate of $\mathrm{CO}_{2}$ volume produced per unit of $\mathrm{O}_{2}$ volume consumed. RER at rest is typically around 0.8 . RER often increases during exercise, and can exceed 1.0 during heavy exertion.

\section{Methods.}

\section{VOLUME ESTIMATION}

Estimates of oxygen supply within the submarine began with a calculation of the net volume of gas within the submarine. The internal volume was calculated by creating a model of the vessel's hull, then subtracting the volumes of all moderate- to large-sized internal objects. Complex structures (vessel hull, snorkel box and pipes, conning towers, cutwaters, structural ribbing, ballast bulkhead walls, and dive planes) were modeled using the engineering modeling software SolidEdge ST7 (version 107.00.00.104x64, Siemens, 2014) to calculate volumes and masses. Volumes and masses of simpler items were calculated manually. Dimensions were obtained both from values published in released documents (e.g., $[3,16,17])$ and by measuring items from published photographs that included measurement stadia. A summary of item measurements and volumes are shown in Table 1. While dimensions were measured from photographs rather than the vessel itself, the resulting model closely matches published scans and drawings of the recovered submarine (Figure 2).

Figure 2. The rendered model, shown as a black outline, compared to grey-filled tracings of the recovered vessel (top view drawn from laser scan [18], side view drawn from published diagram [19]). Some details, such as dive planes and keel ballast weights, are eliminated from the outlines to provide clearer views of the hull. The tracing and diagram show some damage as a result of underwater exposure.

The volumes of the crewmembers were also estimated and subtracted from the internal volume of the vessel. The heights and descriptions of each crewmember were published by the Friends of the Hunley after analysis of the remains by specialists from the Smithsonian Institution [20-30]. The average body mass index of adult male military personnel entering West Point between 1874-1894 was 20.22 ( \pm 1.99 SD); this value was used to compute masses of the crewmembers [31]. The displacement volume of the crew was calculated using a density of 1.05 $\mathrm{g} / \mathrm{mL}$, a reported mean value for military males (range 1.06-1.04 for ages 20-44) [32].

The volume of the ballast water was also calculated and subtracted from the internal volume. In 1902, former crewmember William Alexander published his account of the Hunley operations, including a diagram of the vessel's position in the water column when operating "light," or with the conning towers fully above the waterline. The submerged volume of the 
vessel was calculated using the SolidEdge inspection tool. This volume was used as the displacement volume of the submarine when operating "light." Figure 3 shows the sliced SolidEdge model juxtaposed with the original drawing from the publication by William Alexander. Visual approximation was considered sufficiently accurate to position the cut, as the original drawing was an estimate.

Figure 3. The Hunley's position in the water column when ballasted "light," modified from a sketch in William Alexander's descriptive article [2].

The positive buoyant force on the vessel was then calculated using this submerged volume. Comparison of the buoyant force to the mass of the vessel and internal objects provided the estimated volume of ballast water needed. This water volume was also subtracted from the internal volume of the vessel. Since the calculation of ballast water was considered to be the most sensitive aspect of the methods, all calculations were additionally performed assuming both zero ballast water and full ballast tanks. These additional calculations served to bound the upper and lower limits of the available oxygen supplies, and assess whether the qualitative results of the analysis varied at these extremes.

\section{GAS CONSUMPTION}

To calculate how long the oxygen supply onboard the Hunley could last, it is important to use realistic estimates of crew consumption. Seven of the crewmembers powered the Hunley by turning a hand crank attached to the propeller via a gearing mechanism. Research with arm ergometers has shown that the mean maximum rate of oxygen consumption $\left(\mathrm{VO}_{2}\right)$ for a male performing a sustainable but high level of arm cranking exercise is $3.2 \mathrm{~L} / \mathrm{min}$, and a mean value for moderate but submaximal exercise is $1.5 \mathrm{~L} / \mathrm{min}$. Additionally, moderate changes in the rate of pedaling do not significantly impact the rates of oxygen consumption for a given level of physical exertion [33]. These values are consistent with the expected values for moderate exercise. A range of 1.5-3.2 L/min was therefore used to estimate oxygen consumption by the seven cranking crewmembers.

Lieutenant George Dixon manned the forward position in the submarine, and was in charge of navigation and the torpedo rather than cranking the propeller [21, 24]. His oxygen consumption was therefore estimated as $1.5 \mathrm{~L} / \mathrm{min}$, consistent with someone performing a mild to moderate activity level [13]. The total time of useful consciousness was calculated using Equation 1.

$$
t_{O 2}=\frac{V_{n e t} *\left(F_{O 2 \text { initial }}-F_{O 2 L O C}\right)}{V O_{2}}
$$

This equation predicts the time $\left(\mathrm{t}_{\mathrm{O} 2}\right)$, in minutes, before risk of loss of consciousness from hypoxia. Its variables are net internal volume of the gas space $\left(\mathrm{V}_{\text {net }}\right)$, rate of oxygen consumption $\left(\mathrm{VO}_{2}\right)$, and fractional percentage of oxygen both at the start $\left(\mathrm{F}_{\mathrm{O} 2}\right.$ initial $)$ and where risk of loss of consciousness occurs $\left(\mathrm{F}_{\mathrm{O} 2 \mathrm{LOC}}\right)$. For the purposes of these calculations, fractional percentage is equivalent to partial pressure $\left(\mathrm{F}_{\text {gas }}=\mathrm{p}_{\text {gas }}\right)$ for all gases, as all aspects of this analysis take place at one atmosphere of pressure. 
At the moment the hatches were closed, starting initial fraction of oxygen was estimated as 0.21 ; therefore $\mathrm{pO}_{2}=0.21$ atm was the initial oxygen partial pressure. No studies were found that estimated time of useful consciousness under measured, progressively decreasing oxygen levels. During acute hypoxia, the time of useful consciousness is reduced to minutes for $\mathrm{pO}_{2}$ levels in the range of 0.063-0.10 atm [34-37]. The $0.063 \mathrm{~atm}$ value was used as the minimum cutoff to estimate risk of loss of consciousness, though with progressively decreasing levels it is likely the crew would experience hypoxia before this level. This partial pressure value therefore represents an extreme lower bound. The calculations were also performed assuming risk of loss of consciousness at $\mathrm{pO}_{2}=0.10$ atm to provide a more conservative upper bound.

A respiratory exchange ratio (RER) of 0.95 was used to calculate $\mathrm{CO}_{2}$ production by the crew. RER is the ratio of volume of $\mathrm{CO}_{2}$ produced per volume of $\mathrm{O}_{2}$ consumed in a breath. The total time until risk of symptomatic hypercapnia $\left(\mathrm{t}_{\mathrm{CO} 2}\right)$ was calculated in minutes using Equation 2. $\mathrm{CO}_{2}$ absorption by the water in the ballast tanks was evaluated as a potential additional factor, but was determined to be negligible ( $<7.0 \mathrm{e}-4 \%$ change in predicted $\mathrm{CO}_{2}$ levels) because a large amount of $\mathrm{CO}_{2}$ is being generated within a small gas volume, with exposure to a small surface area of water.

$$
t_{\mathrm{CO} 2}=\frac{V_{n e t} * F_{\mathrm{CO} 2}}{\left(\mathrm{VO}_{2}\right) * R E R}
$$

$\mathrm{F}_{\mathrm{CO} 2}$ represents the fraction of $\mathrm{CO}_{2}$ at which the crew experiences sufficient symptoms to recognize the need for ventilation and opens the hatches. Combining Equations 1 and 2 results in Equation 3, which calculates the ratio between time to hypoxia and time to symptomatic hypercapnia. Equation 3 does not include gas volume as a variable, and therefore allows some analysis of the relative time scales without complex volumetric calculations.

$$
\frac{t_{O 2}}{t_{C O 2}}=R E R * \frac{F_{O 2 \text { initial }}-F_{O 2 L O C}}{V O_{2}}
$$

Tests of $\mathrm{CO}_{2}$ inhalation indicate that most subjects experience a physiologically noticeable, statistically significant appearance of symptoms at approximately $\mathrm{pCO}_{2}=0.05$ atm, with definite symptoms expected in subjects above $\mathrm{pCO}_{2}=0.07$ atm at atmospheric pressures [15, 38-40]. Under resting conditions $7 \% \mathrm{CO}_{2}$ has been reported as tolerable for long periods, but with difficulty. Haldane (1892) reported that when $\mathrm{CO}_{2}$ concentration progressively rose above 5\%, “...the breathing was painfully labored, and required so much exertion as to produce great exhaustion" [41]. Since the Hunley crew were mostly exercising, $\mathrm{pCO}_{2}=0.05 \mathrm{~atm}$ was therefore used as a cutoff limit. Additional calculations were performed with $\mathrm{pCO}_{2}=0.07$ atm for conservatism.

Note that while $\mathrm{VO}_{2}$ and $\mathrm{VCO}_{2}$ are conventionally reported as $\mathrm{L} / \mathrm{min} \mathrm{STPD}$ (standard temperature and pressure, dry: $0^{\circ} \mathrm{C}$, barometric pressure $760 \mathrm{mmHg}$ ), these rates have been converted to ATPD (atmospheric temperature, estimated at $30^{\circ} \mathrm{C}$ for the interior of the Hunley), approximately $10 \%$ higher. Owing to the cranking movement of the men inside a small volume, complete mixing of gas within the hull was assumed. 
Since former crewman William Alexander reported candle tests to determine the crew's oxygen supply [2], the estimated duration of the candle flame was also included in the calculations.

Most sources report wick-fed flames extinguish in atmospheres of approximately $17 \%$, with only one source indicating flames surviving as low as $15.7 \%$ oxygen [42-44]. It has also been observed that matches burn with difficulty in air when the $\mathrm{CO}_{2}$ level exceeds 5\% [41]. The value of $\mathrm{pO}_{2}=0.17$ was therefore used in $\mathrm{Eq} 1$ to estimate the duration of the flame.

\section{Results.}

\section{VOLUME ESTIMATION}

Table 1 shows a summary of calculated volumes and masses for all non-trivial objects aboard the Hunley.

Table 1. Summary of masses and volumes of all non-trivial objects aboard the Hunley. A full listing of items and estimated dimensions is freely available for non-commercial use by request to the authors.

\begin{tabular}{|l|c|c|}
\hline \multicolumn{1}{|c|}{ Object } & $\begin{array}{c}\text { Volume } \\
\left(\mathbf{c m}^{\mathbf{3}}\right)\end{array}$ & $\begin{array}{c}\text { Mass } \\
(\mathbf{k g})\end{array}$ \\
\hline Ballast blocks (internal) & 277273 & 2024 \\
\hline Ballast blocks (keel) & --- & 1369 \\
\hline Bench, main crew & 68447 & 34 \\
\hline Crank & 10963 & 168 \\
\hline Crew & 477810 & 502 \\
\hline Internal medium-sized objects* & 152208 & --- \\
\hline All medium-sized objects ${ }^{+}$ & --- & 643 \\
\hline Hull assembly (from SolidEdge) ${ }^{\ddagger}$ & $\begin{array}{l}\text { \$ } \\
\text { (internal) }\end{array}$ & 4408 \\
\hline TOTALS & $\mathbf{8 0 0 6 6 1 2}$ & $\mathbf{8 5 0 5}$ \\
\hline Calculated ballast water & 394026 & 404 \\
\hline
\end{tabular}

* Includes: bellows, bellows pipe, bench (Dixon's), canteens (8), cask/barrel, compass box, copper plate, crank wall mounts, flywheel, gears, piping, pumps (aft and fore), ribbing, rudder control rods, shelf, and various tools

+ Includes: bellows pipe, bench (Dixon's), canteens (8), cask/barrel, chain (primary), chain (spare), compass box, copper plate, crank wall mounts, flywheel, gears, piping, propeller, pumps (fore and aft), rudder, rudder control rods, shelf, and various tools

$\$$ Includes: central hull, bow and stern tapered hulls, bow and stern cast pieces, snorkel box and pipes, conning towers, cutwater, ribbing through hull/bow/stern (mass only), dive planes 
The displaced water volume was calculated as $9.31 \mathrm{~m}^{3}$, resulting in a required ballast water volume of $0.39 \mathrm{~m}^{3}$. This ballast volume results in a net internal gas volume of $7.61 \mathrm{~m}^{3}$. Figure 4 shows the calculated volume of ballast water.

Figure 4. Cutaway side view of the HL Hunley model with calculated ballast levels. Crosshatching indicates water volume.

A net internal volume of $7.61 \mathrm{~m}^{3}(7613 \mathrm{~L})$ with $21 \%$ oxygen provides $1599 \mathrm{~L}$ of oxygen at the moment the conning tower hatches are closed. All calculations were additionally performed assuming zero ballast water and full ballast tanks, which provided $1682 \mathrm{~L}$ and $1351 \mathrm{~L}$ of initial oxygen, respectively.

\section{GAS CONSUMPTION}

Equations 1 and 2 were used to calculate the estimated times until risk of hypoxia/hypercapnia for the upper and lower consumption levels as well as for the three initial oxygen volumes. Levels of oxygen and carbon dioxide were also calculated as functions of time. The results of these calculations are shown numerically in Table 2 and graphically in Figure 5.

Table 2. Calculated times (minutes) until risk of hypoxia and hypercapnia. Minimum, calculated, and maximum volumes represent 1351, 1599, and $1682 \mathrm{~L}$ of oxygen upon closing the hatches, respectively. Oxygen consumption rates indicate rates for the 7 working crewmembers, with Dixon consuming $1.5 \mathrm{~L} / \mathrm{min}$.

\begin{tabular}{|c|c|c|c|c|c|c|}
\hline \multirow{2}{*}{$\begin{array}{l}\text { VOLUME } \\
\text { (L) }\end{array}$} & \multirow{2}{*}{$\begin{array}{c}\mathrm{O}_{2} \\
\text { CONS. } \\
\text { RATE } \\
\text { (L/min) } \\
\end{array}$} & \multicolumn{2}{|c|}{ Hypercapnia } & \multicolumn{2}{|c|}{ Hypoxia } & \multirow{2}{*}{$\begin{array}{c}\begin{array}{c}\text { Candle } \\
\text { Extinguish }\end{array} \\
\mathrm{O}_{2} 0.17 \mathrm{~atm}\end{array}$} \\
\hline & & $\mathrm{CO}_{2} 0.05 \mathrm{~atm}$ & $\mathrm{CO}_{2} 0.07 \mathrm{~atm}$ & $\mathrm{O}_{2} 0.063 \mathrm{~atm}$ & $\mathrm{O}_{2} 0.1 \mathrm{~atm}$ & \\
\hline \multirow{2}{*}{ MIN } & 1.5 & 28 (minutes) & 40 (minutes) & 79 (minutes) & 59 (minutes) & 22 (minutes) \\
\hline & 3.2 & 14 & 20 & 40 & 30 & 11 \\
\hline \multirow{2}{*}{ CALC } & 1.5 & 33 & 47 & 93 & 70 & 25 \\
\hline & 3.2 & 17 & 24 & 47 & 35 & 13 \\
\hline \multirow{2}{*}{ MAX } & 1.5 & 35 & 49 & 98 & 73 & 27 \\
\hline & 3.2 & 18 & 25 & 49 & 37 & 13 \\
\hline
\end{tabular}

Figure 5. Levels of oxygen and carbon dioxide as functions of time, for two different rates of oxygen consumption for the working crew (A: $1.5 \mathrm{~L} / \mathrm{min}, \mathrm{B}: 3.2$

$\mathrm{L} / \mathrm{min}$ ). Dixon's oxygen consumption was held constant at $1.5 \mathrm{~L} / \mathrm{min}$.

Calculations performed at the calculated, maximum, and minimum internal gas volumes of the vessel.

The predicted gas levels in Figure 5 are truncated where either hypoxia or hypercapnia would independently cause debilitating physiological symptoms that would force a reduction in activity level $\left(\mathrm{pO}_{2}<0.063 \mathrm{~atm}\right.$ or $\left.\mathrm{pCO}_{2}>0.07 \mathrm{~atm}\right)$.

Equation 3 was used to calculate the Respiratory Exchange Ratio that would be required for hypoxia to occur more quickly than hypercapnia $\left(t_{\mathrm{O} 2} / \mathrm{t}_{\mathrm{CO} 2}<1\right)$. For the most conservative 
combination of values $\left(\mathrm{pO}_{2}=0.10 \mathrm{~atm}, \mathrm{pCO}_{2}=0.07 \mathrm{~atm}\right)$, an RER of less than 0.64 is required. Other combinations of $\mathrm{pO}_{2}$ and $\mathrm{pCO}_{2}$ yielded even lower RER values.

William Alexander reported a time of 25 minutes before the candle flame spontaneously extinguished, with the crew submerged and cranking for a total of 2 hours 35 minutes before surfacing. The snorkel system was not in use since the test took place on the ocean floor [2]. The above calculations show a range of possible times for the candle flame to be extinguished by hypoxia; they range from 11 to 27 minutes. At the calculated initial gas volume, the atmosphere would reach $17 \%$ oxygen and the candle would extinguish after 25 minutes if all crewmembers were consuming $1.5 \mathrm{~L} / \mathrm{min}$. After 25 minutes at this work rate the submarine atmosphere would be $3.7 \% \mathrm{CO}_{2}$. After the first 25 minutes, the crew would have had to reduce their oxygen consumption to $0.51-0.78 \mathrm{~L} / \mathrm{min}$ to maintain oxygen supply for an additional 130 minutes $(0.1$ $0.063 \mathrm{~atm}$ hypoxia cutoff values, respectively). These values are consistent with rest to mild activity; however, by the end of this time period the atmosphere would be $11.6-15.2 \% \mathrm{CO}_{2}$. Alternatively, matching the reported abort time of 2 hours 35 minutes would require a work rate of 0.196-0.275 L/min per crewmember (0.05-0.07 atm $\mathrm{CO}_{2}$ cutoff values, respectively). If instead the crew maintained a constant work rate of $1.5 \mathrm{~L} / \mathrm{min}$, they would have definite symptoms of hypercapnia $\left(\mathrm{pCO}_{2}=0.07\right.$ atm) by 47 minutes after the start of the test, or 22 minutes after the candle would have extinguished.

\section{Discussion.}

The crew of the Hunley was reportedly commanded to maintain the vessel at the surface and to refrain from submersion $[1,45]$. While the Hunley was reported to be at the surface during the attack by survivors from the Housatonic, they could theoretically have submerged afterwards, possibly to avoid detection [1]. The order was documented 14 years after the attack, and so, must be treated with some skepticism. However, assuming the order was given and followed, the conning tower hatches were above the water line at all times, even following the attack, and could have been opened at any time. If the crew did submerge, even with full ballast tanks there is a calculated minimum of 10 minutes and a realistic estimate of 30 minutes between the onset of hypercapnia symptoms and the onset of hypoxia sufficient to cause unconsciousness (Table 2). The times were calculated for the two gases independently, which adds an additional degree of conservatism because rising inspired $\mathrm{CO}_{2}$ levels increase levels of alveolar $\mathrm{O}_{2}$, thereby further lengthening the time until risk of hypoxia [46]. These calculations are even more conservative if limited mixing occurred with the hatch open since $\mathrm{CO}_{2}$ is slightly denser than air. Additionally, an RER of 0.64 is below physiologically possible limits and therefore indicates that hypoxia will not occur before symptomatic hypercapnia, regardless of internal gas volume. The crucial result of this analysis is that hypoxia was not a likely risk for the crew of the Hunley before noticeable symptoms of hypercapnia would have occurred.

While hypoxia may go unnoticed, hypercapnia is impossible to ignore. Figure 5 clearly shows that $\mathrm{CO}_{2}$ production becomes problematic long before hypoxia becomes a realistic concern, for all combinations of gas volume and oxygen consumption. Even with conservative calculations, the entire crew would have been experiencing noticeable hyperventilation, gasping for breath, choking, symptoms of panic, and possibly physical pain a minimum of 10 minutes 
before any risk of loss of consciousness. It is not plausible that the crew would have ignored these strong symptoms and not attempted to open the hatches. Hypercapnia is not consistent with the evidence that the crew remained at their stations when the Hunley came to rest on the bottom.

This study and Haldane's test are also both consistent with the scientific analysis of the atmosphere of the sunken submarine HMS Thetis [47]. Following the sinking of the Thetis, four crewmembers escaped and reported the measured atmospheric composition onboard the sub at the time of the escape. The remaining crewmembers did not survive. In an attempt to recreate the final moments of the submariners remaining on board, and to determine if they were killed by hypoxia or hypercapnia, British scientists enclosed themselves in a sealed chamber, wherein they had to rebreathe their own gas supply while remaining sedentary. Inside the chamber was a volume of $967 \mathrm{~L} /$ person (note that the internal hull volume of the Hunley was a calculated 952 $\mathrm{L} /$ person, a difference of less than $2 \%$ from the experiment). The scientists started with $6.1 \%$ carbon dioxide in the chamber, but only managed to rebreathe this gas mixture for 30 minutes before being forced to purge the chamber with air to lower the $\mathrm{CO}_{2}$ levels. After another 30 minutes, all scientists were described as "panting severely," despite the fact that oxygen levels had been maintained at a physiologically comfortable level of no lower than approximately 18 percent [47].

The description of the candle tests to determine air supply was written in a newspaper article in 1902, 38 years after the sinking of the vessel. Alexander reported that the candle extinguished 25 minutes after submergence, and that the crew remained submerged, cranking, and able to bring the submarine back to the surface after 2 hours and 35 minutes [2]. Three scenarios were explored: 1) A constant work rate to match the reported abort time, 2) One work rate to match the candle time then a second rate to match the abort time, and 3) A constant work rate to match only the candle time. The oxygen consumption values required by these three scenarios are discussed above. However, assuming the first scenario, oxygen consumption rates of $0.196-0.275 \mathrm{~L} / \mathrm{min}$ are unrealistically low for adult males as the oxygen required to maintain basal metabolic rate would be $0.22 \mathrm{~L} / \mathrm{min}$ for the eight crewmembers $(3.5 \mathrm{~mL} / \mathrm{min} / \mathrm{kg}, 502 \mathrm{~kg}$ total for all crewmembers) [48]. The second scenario is also not likely, as $\mathrm{CO}_{2}$ percentages of 11.6-15.2\% are well above tolerable levels and would have been intolerably painful if not incapacitating. The third scenario predicts an abort after 47 minutes, far shorter than the reported time.

No combination of gas consumption rates could be found that matched both the candle time and the abort time. Similarly, when the calculations were re-performed using hypoxia as a driving factor in the decision to abort, no combination of gas consumption rates could match both times. It seems most likely that, while the time until the loss of the candle flame may have been accurate, the report of 2 hours 35 minutes was either a deliberate exaggeration or an inaccurate estimate made many years after the actual experience. Indeed, Alexander's account relates a test wherein all crewmembers, despite immersion in total darkness and a complete lack of communication, simultaneously and in unison declared the word "UP" to signal the end of the test [2]. This unlikely degree of synchrony implies an idealized remembrance of the test. 


\section{Conclusion.}

The crew of the Hunley would have suffered symptomatic hypercapnia before any risk of hypoxia, and most likely would not have remained seated peacefully at their stations. High carbon dioxide levels have been shown to cause severe psychological discomfort and panic, in addition to the physical symptoms. They are impossible to willingly ignore, and they are impossible to sleep through. The theory that a crew of eight men voluntarily submitted to painful asphyxiation by hypercapnia in a cold, dark environment, without any attempt at escape, defies human nature. Upon raising the downed submarine $S$-51, submariner Swede Momsen remembered for decades "the horribly contorted faces and the flesh-shredded fingers of those in the $S$-51 who had not drowned immediately, who instead spent the final minutes of their lives trying to claw their way out of a steel coffin." [49] This analysis suggests strongly that asphyxiation was not the probable cause of the sinking of the H.L. Hunley, and that the crew's final moments were most likely, in the words of Warren Lasch, "quick and decisive." [9]

The primary limitation of this study is the degree of biological variability inherent to hypoxia and hypercapnia. There were no firm cutoffs found to quantify risk of loss of consciousness in gradually decreasing oxygen levels, or risk of symptoms in gradually increasing carbon dioxide levels. This study attempted to minimize the risks from this limitation by performing calculations for multiple cutoff levels, including upper and lower bounds. The use of exact vessel dimensions could enhance the precision of the calculations to a certain degree; however, current calculations show that varying the internal gas volume has little effect on the qualitative conclusions.

\section{References and Notes:}

[1] Kloeppel JE. Danger beneath the waves: a history of the confederate submarine H.L. Hunley. College Park, Georgia: Adele Enterprises; 1987.

[2] Alexander WA. The true stories of the Confederate submarine boats. The Daily Picayune. New Orleans, LouisianaSunday June 29, 1902. p. 6-7.

[3] Murphy LE, Lenihan DJ, Amer CF, Russell MA, Neyland RS, Wills R, et al. H.L. Hunley site assessment. In: Murphy LE, editor. Cultural Resources Management Professional Papers. Santa Fe, New Mexico: Submerged Cultural Resources Unit, Intermountain Region, National Park Service; 1998. p. 198.

[4] Tale of the torpedo. The Blue Light. Charleston, South Carolina: Friends of the Hunley; 2014. p. 8-11.

[5] More surprises discovered in H.L. Hunley. [press release]. Charleston, South Carolina: Friends of the Hunley; May 4, 2001. www.hunley.org

[6] Hunley only had crew of eight. [press release]. Charleston, South Carolina: Friends of the Hunley; Nov 2, 2001. www.hunley.org

[7] Beauregard GT. Torpedo service in the harbor and water defences of Charleston. Southern Historical Society Papers. 1878;5:145-61.

[8] Hicks B, Kropf S. Raising the Hunley: the remarkable history and recovery of the lost Confederate submarine: Presidio Press; 2007. 
[9] Eight Hunley crewmembers found. [press release]. Charleston, South Carolina: Friends of the Hunley; April 16, 2001. www.hunley.org

[10] Excavation continues, so does the mystery. [press release]. Charleston, South Carolina: Friends of the Hunley; Nov 30, 2001. www.hunley.org

[11] Sharrer EA, Darrah SG, Harris MS, Jacobsen M. Marine macrofaunal analysis of the interior sediments from the H.L. Hunley (38CH1651). Geological Society of America Annual Meeting. Charleston, South Carolina: Geological Society of America; 2001.

[12] Martin A, Case RG. Secret weapon of the Confederacy. National Geographic Channel; 2011. p. 90 mins.

[13] Åstrand P-O, Rodahl K. Textbook of work physiology. United States of America: McGrawHill, Inc.; 1977.

[14] Colasanti A, Salamon E, Schruers K, Van Diest R, Van Duinen M, Griez EJ. Carbon dioxide-induced emotion and respiratory symptoms in healthy volunteers.

Neuropsychopharmacology. 2008;33:3103-10.

[15] Poma SZ, Milleri S, Squassante L, Nucci G, Bani M, Perini GI, et al. Characterization of a $7 \%$ carbon dioxide $(\mathrm{CO} 2)$ inhalation paradigm to evoke anxiety symptoms in healthy subjects. J Psychopharmacol. 2005;19:494-503.

[16] Crew bench to be removed in preparation for Hunley conservation. [press release]. Charleston, South Carolina: Friends of the Hunley; Jan 28, 2005. www.hunley.org

[17] Scientists uncover evidence of explosion. [press release]. Charleston, South Carolina: Friends of the Hunley; 2013. www.hunley.org

[18] DeVine D. Mapping the CSS Hunley. Professional Surveyor. 2002;22:6-16.

[19] Jacobsen M, Blouin V, Shirley W. Does erosion corrosion account for intriguing damage to the Civil War submarine H.L. Hunley? Marine Technology Science Journal. 2012;46:38-48.

[20] Crewman profile: Becker. [press release]. Charleston, South Carolina: Friends of the Hunley; Apr 12, 2004. www.hunley.org

[21] Crewman profile: Dixon. [press release]. Charleston, South Carolina: Friends of the Hunley; Apr 12, 2004. www.hunley.org

[22] Lumpkin. [press release]. Charleston, South Carolina: Friends of the Hunley; Apr 13, 2004. www.hunley.org

[23] Arnold Becker. [press release]. Charleston, South Carolina: Friends of the Hunley; Apr 12, 2004. www.hunley.org

[24] Lt. George E. Dixon. [press release]. Charleston, South Carolina: Friends of the Hunley; Apr 12, 2004. www.hunley.org

[25] Frank Collins. [press release]. Charleston, South Carolina: Friends of the Hunley; Apr 14, 2004. www.hunley.org

[26] Joseph Ridgaway. [press release]. Charleston, South Carolina: Friends of the Hunley; Apr 13, 2004. www.hunley.org

[27] Corporal J.F. Carlsen. [press release]. Charleston, South Carolina: Friends of the Hunley; Apr 15, 2004. www.hunley.org

[28] Miller. [press release]. Charleston, South Carolina: Friends of the Hunley; Apr 14, 2004. www.hunley.org

[29] James A. Wicks. [press release]. Charleston, South Carolina: Friends of the Hunley; Apr 15, 2004. www.hunley.org

[30] Jacobsen M. Project 04-106, H.L. Hunley project: 2004 archaeological findings and progress report. Department of Defense Legacy Resource Management Program2005. 
[31] Cuff T. The body mass index values of mid-nineteenth-century West Point cadets: a theoretical application of Waaler's curves to a historical population. Historical Methods. 1993;26:171-82.

[32] Kryzywicki HJ, Chinn KS. Human body density and fat of an adult male population as measured by water displacement. Fitzsimons General Hospital, Denver, Colorado: US Department of Commerce/National Bureau of Standards/Institute for Applied Technology; 1966.

[33] Smith PM, Price MJ, Doherty M. The influence of crank rate on peak oxygen consumption during arm crank ergometry. Journal of Sports Sciences. 2001;19:955-60.

[34] Hall F. Interval of useful consciousness at various altitudes. J Appl Phys. 1949;1:490-5.

[35] Hall F, Hall K. Effect of adding carbon dioxide to inspired air on consciousness time of man at altitude. Experimental Biology and Medicine. 1951;76:140-2.

[36] Mackenzie CG, Riesen AH, Bailey JR, Tahmisian TN, Crocker PL. Duration of consciousness in anoxia at high altitudes. J Aviation Medicine. 1945;16:156-74.

[37] Webster AP, Reynolds OE. High altitude, high velocity flying with special reference to the human factors. J Aviation Medicine. 1950;21:237-45.

[38] Bailey JE, Argyropoulos SV, Kendrick AH, Nutt DJ. Behavioral and cardiovascular effects of $7.5 \%$ CO2 in human volunteers. Depression and Anxiety. 2005;21:18-25.

[39] Stegen K, Neujens A, Crombez G, Hermans D, Van de Woestijne KP, Van den Bergh O. Negative affect, respiratory reactivity, and somatic complaints in a $\mathrm{CO} 2$ enriched air inhalation paradigm. Biological Psychology. 1998;49:109-22.

[40] Woods SW, Charney DS, Goodman WK, Heninger GR. Carbon dioxide-induced anxiety: behavioral, physiologic, and biochemical effects of carbon dioxide in patients with panic disorders and healthy subjects. Arch Gen Psychiatry. 1988;45:43-52.

[41] Haldane J, Smith JL. The physiological effects of air vitiated by respiration. J Pathology and Bacteriology. 1892;1:168-86.

[42] Blount B. Analysis of a sample of air which extinguishes flame. Analyst. 1906;31:144-7.

[43] Clowes F. The composition of the extinctive atmospheres produced by flames. Proc R Soc London. 1894;57:353-7.

[44] Dollwig HC, Kolls AC, Loevenhart AS. Some observations on the effect of the partial pressure of oxygen on combustion. J Am Chem Soc. 1917;39:2224-31.

[45] Quinn-Smith R. Parallel destinies. The Blue Light. Charleston, South Carolina: Friends of the Hunley; 2009. p. 6-10.

[46] Otis AB. Quantitative relationships in steady-state gas exchange. Handbook of Physiology Respiration I. 1964. p. 681-98.

[47] Alexander W, Duff P, Haldane J, Ives G, Renton D. After-effects of exposure of men to carbon dioxide. Lancet. 1939;234:419-20.

[48] Kwan M, Woo J, Kwok T. The standard oxygen consumption value equivalent to one metabolic equivalent $(3.5 \mathrm{~mL} / \mathrm{min} / \mathrm{kg})$ is not appropriate for elderly people. Int J Food Sci Nutr. 2004;55:179-82.

[49] Maas P. The Terrible Hours, p55. United States of America: HarperCollins Publishers Inc.; 1999. 

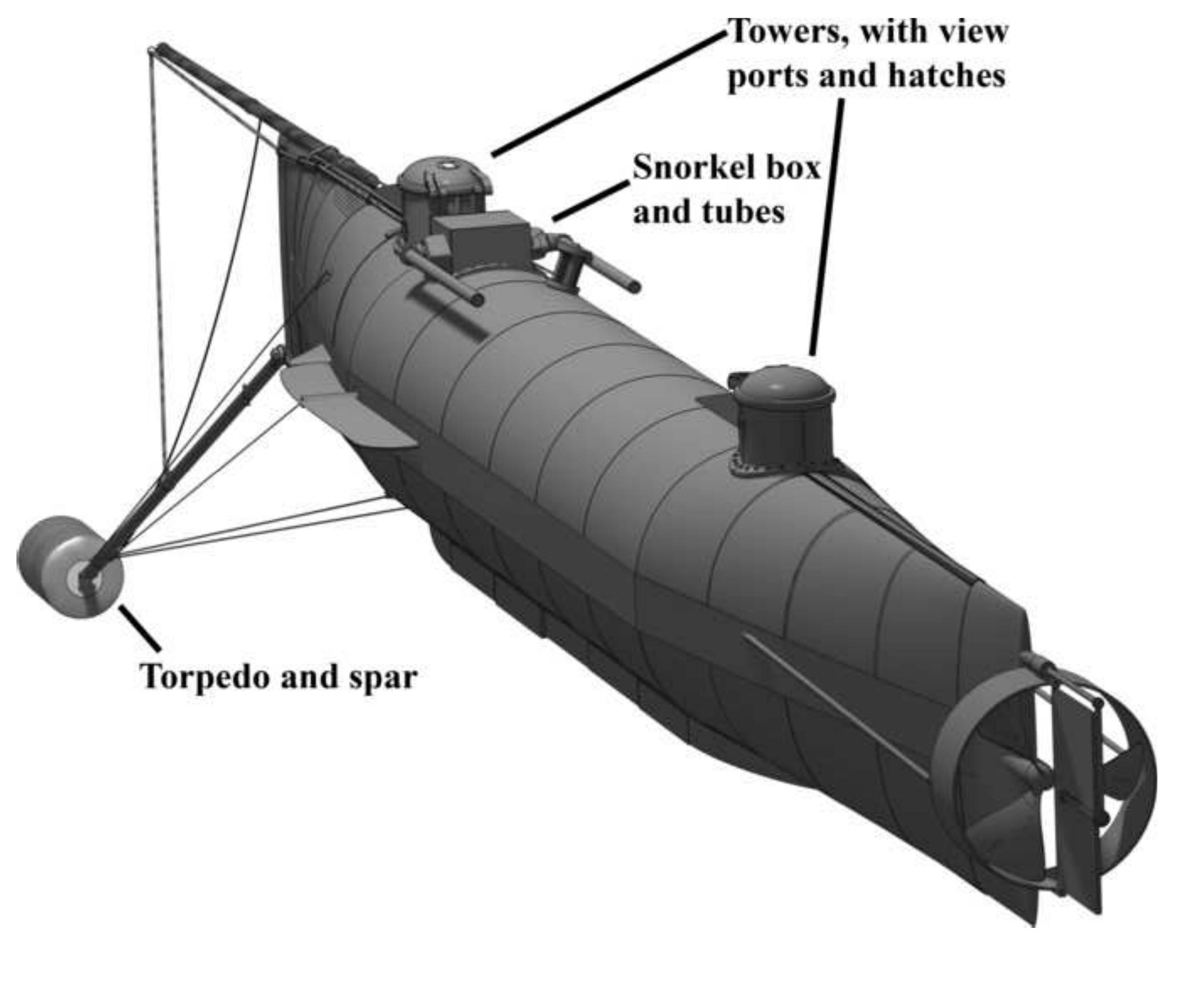

列

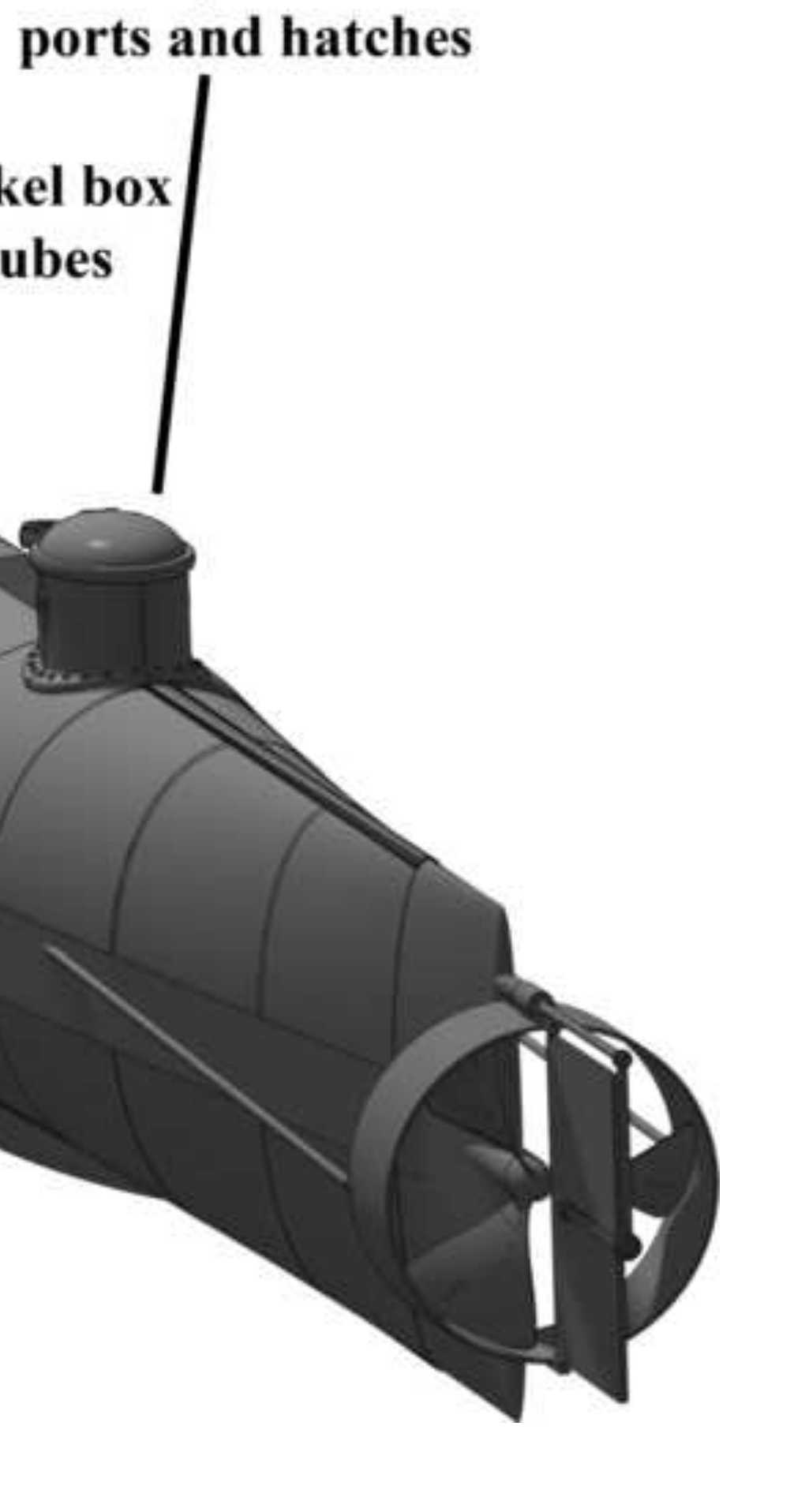

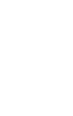

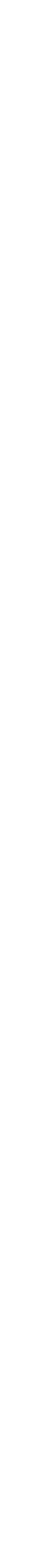



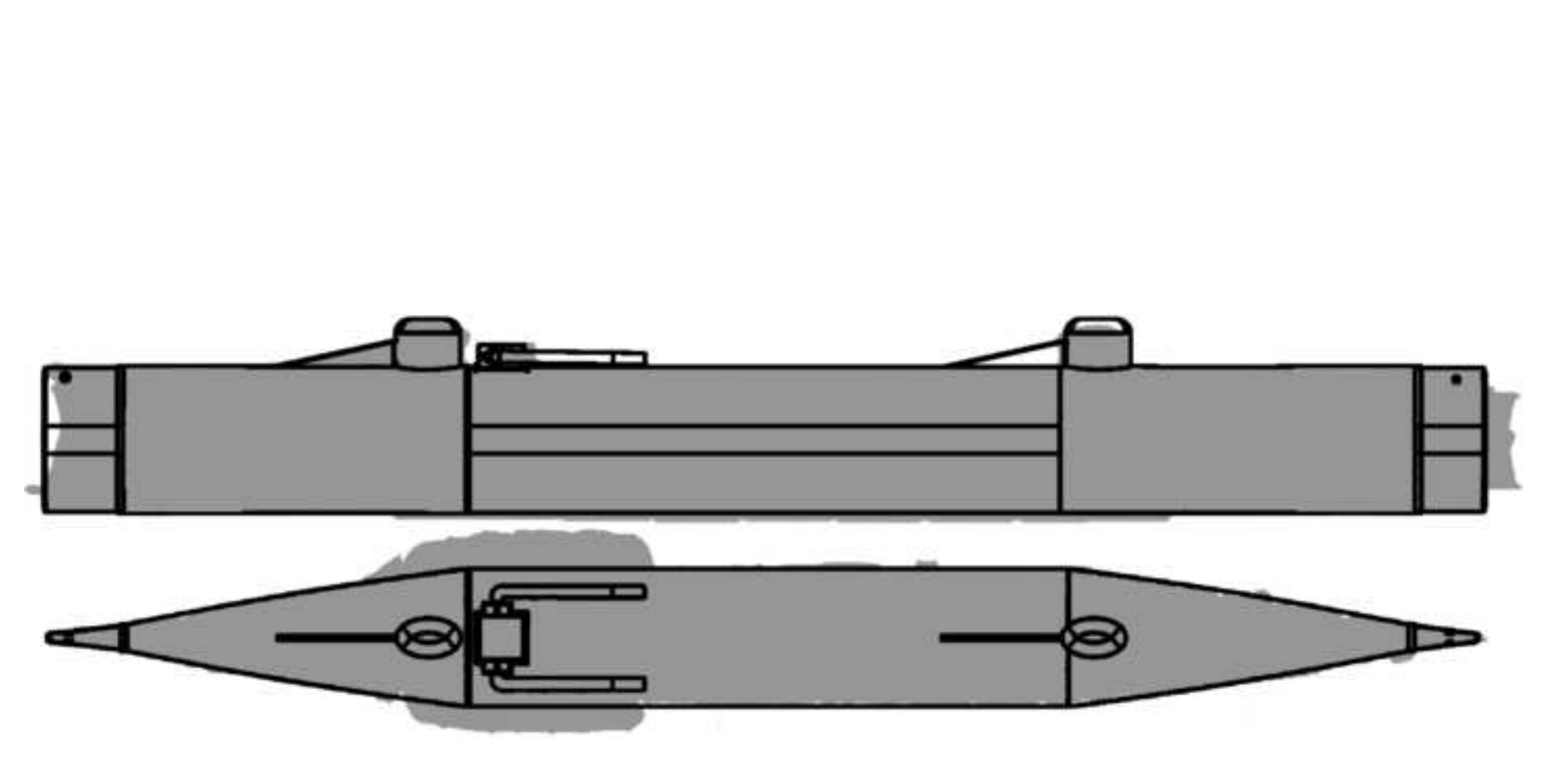

.
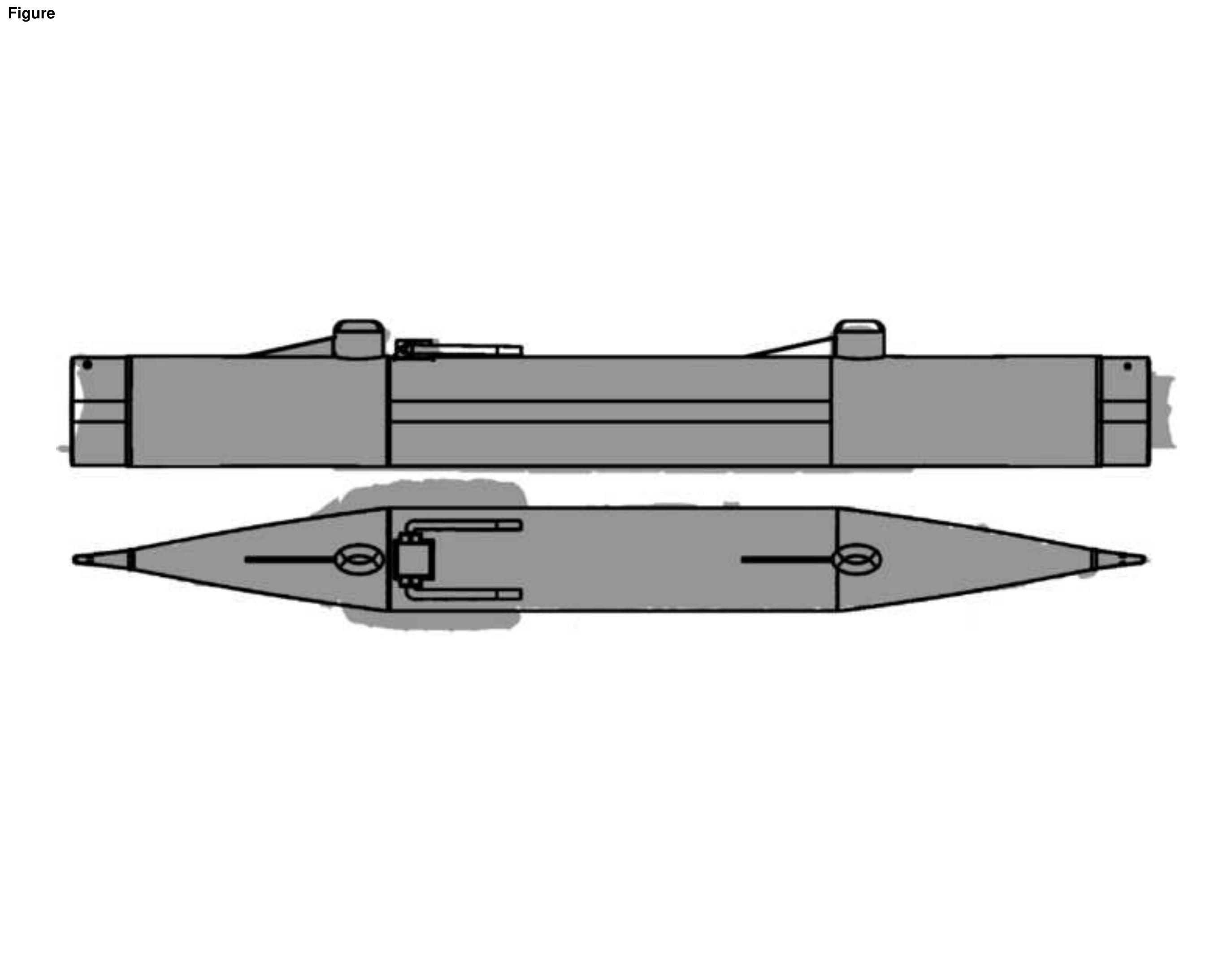


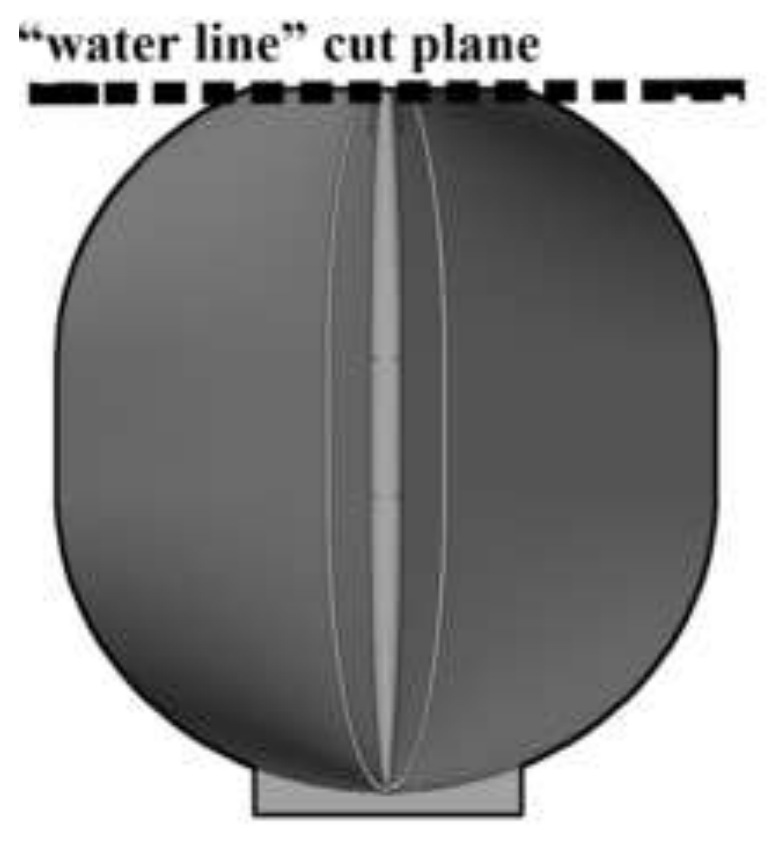

3D SolidEdge model Side view

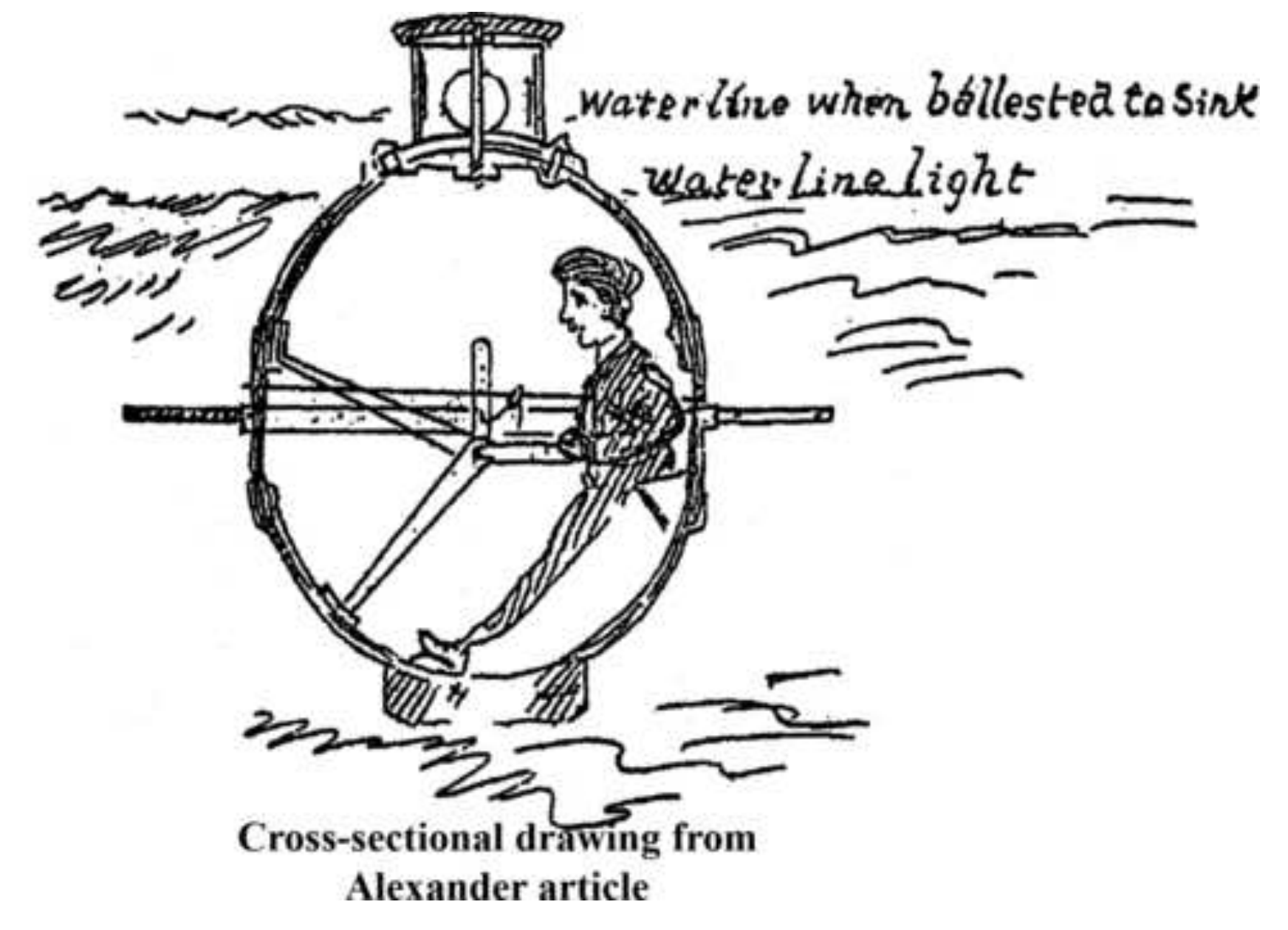


(A)

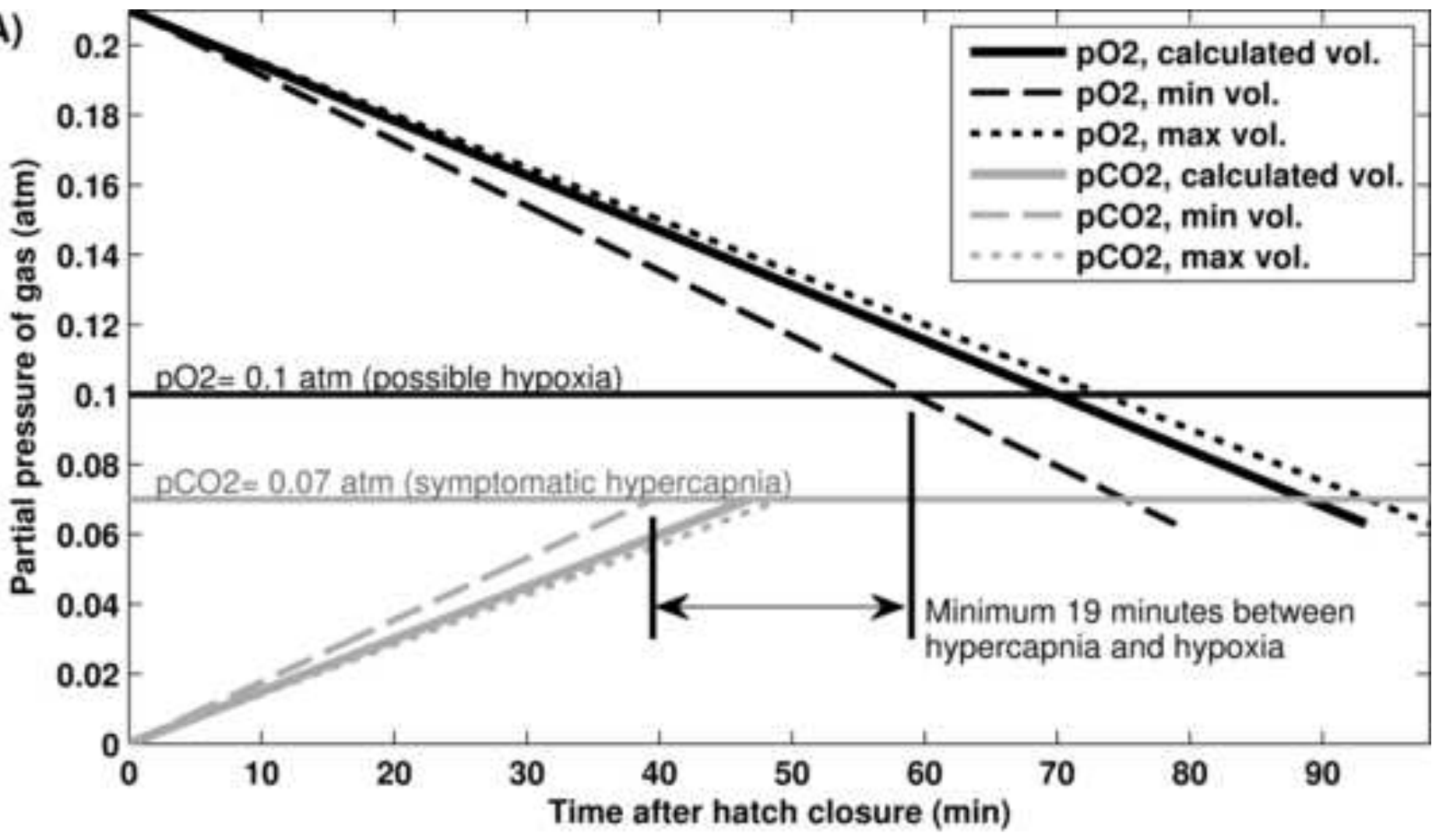

(B)

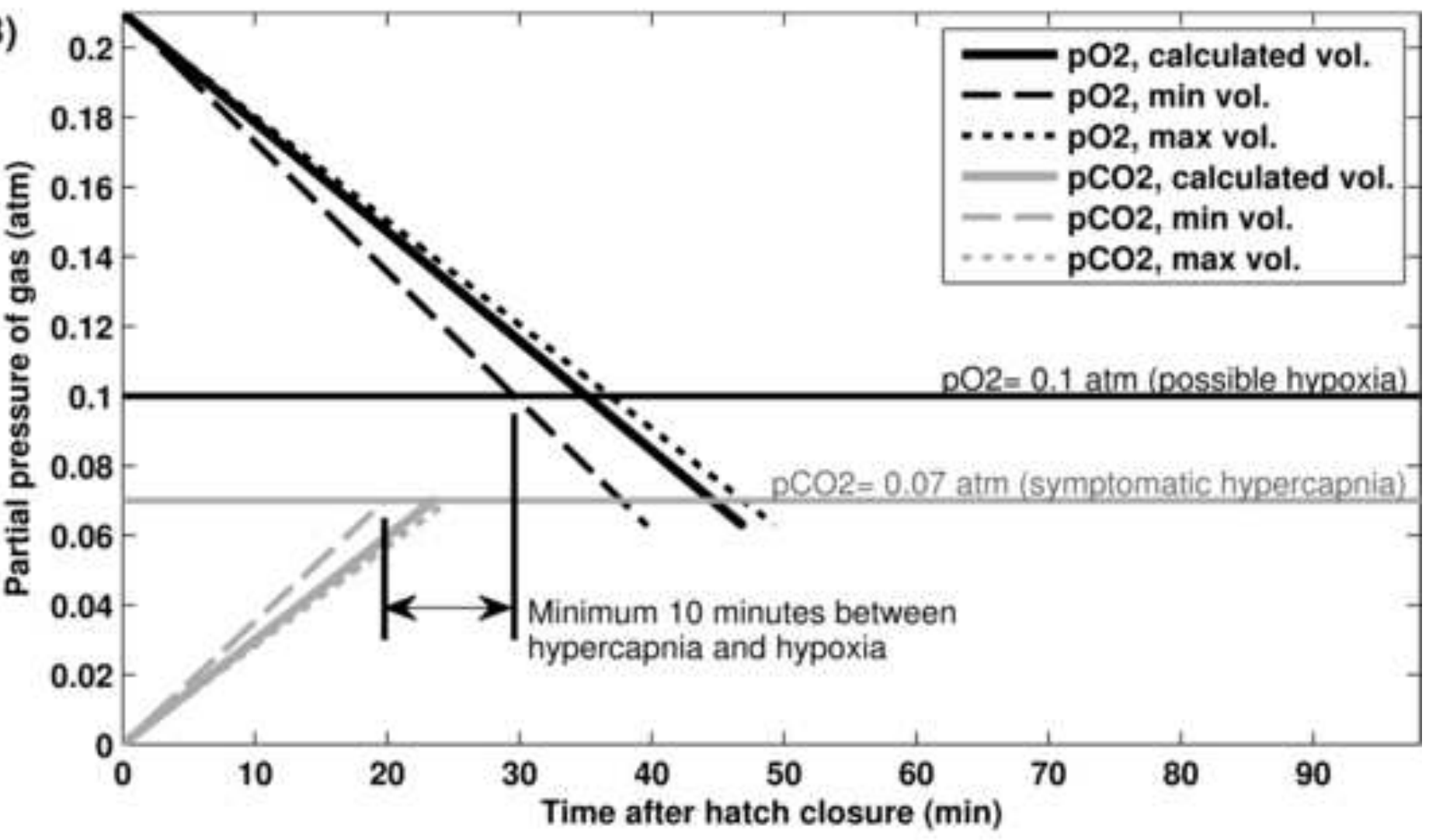

